\title{
Spontaneous Pneumothorax: New Horizons
}

\author{
Avinash Aujayeb \\ Respiratory Department, Northumbria Healthcare NHS Foundation Trust, Northumbria Way, \\ Cramlington NE23 6NZ, UK; avinash.aujayeb@nhct.nhs.uk; Tel.: +44-77-0334-3329
}

Received: 7 February 2021; Accepted: 12 February 2021; Published: 18 February 2021

\begin{abstract}
Spontaneous pneumothorax can be divided into two categories: primary and secondary. The management of each one depends on resource availability, physician preference, and procedural capability, and is broadly based on guidelines that are over a decade old. Emerging evidence from three recent randomized controlled trials on ambulatory pneumothorax pathways are exciting and herald a new era for management of spontaneous pneumothorax. These three trials and their implications are discussed.
\end{abstract}

Keywords: pneumothorax; ambulatory management; pleural vent

\section{Introduction}

Pneumothorax occurs when air enters the pleural space. The first description dates back to the 15th century. The 19th century French physician Rene Laennec described pneumothorax in the context of mycobacterium tuberculosis infection, but also acknowledged spontaneous pneumothorax as "“pneumothorax simple"" [1]. Spontaneous pneumothorax occurs without trauma or iatrogenic injury. British Thoracic Society 2010 guidelines suggests subdividing spontaneous pneumothorax into primary and secondary [2]. Primary spontaneous pneumothorax (PSP) is defined as occurring without pre-existing lung disease. Secondary spontaneous pneumothorax (SSP) occurs with pre-existing lung disease, or in those who are older than 50, or in individuals with significant smoking history [2].

Annual incidence of pneumothorax rate is, per 100,000, approximately, 40.7 in men and 15.6 in women in the United Kingdom [2]. Presentation with sudden onset pleuritic pain and dyspnoea is well described. British Thoracic Society (BTS) guidelines suggest that conservative management, needle aspiration (NA), and intercostal drain (ICD) insertion are all suitable initial treatment modalities. SSPs can either be observed in hospital or treated with an ICD [2]. Hospital stay for patients requiring drainage is 6-8 days [3]. However, the precise definition of PSP is currently being debated.

Traditional teaching suggests patients with PSP to have "normal lungs", but increasingly macroscopic and microscopic structural abnormalities characterized by bleb and bullae formation, distal airways inflammation, "pleural porosity", and emphysema-like changes (ELCs) are noted [2,4].

Blebs and bullae are detected in $80-90 \%$ of thoracic computed tomogram scans of PSP, but only in $20 \%$ of control groups. The majority of blebs do not rupture and recurrence rates with bullectomy range is between 10 and $25 \%$. In a retrospective study, 20 patients with PSP were compared to 20 with SSP, and compared to 40 patients without pneumothorax. Areas thought to be ELC were found in smokers with PSP, suggesting underlying alveolar abnormalities. Hence, PSP does not occur in "normal lungs" [4,5].

NA and ICD insertion are well established treatment modalities. A Cochrane analysis was performed in 2017 to compare NA and ICD insertion. Six randomized trials were selected out of 2332 studies [6]. They lacked statistical power, but showed a difference in success rates when an ICD was used (risk ratio (RR) $0.78,95 \%$ confidence interval (CI) 0.69 to $0.89 ; 435$ participants, 6 studies; moderate-quality evidence). NA was associated with less inpatient stays and less adverse events. 
In selected cases, conservative management might be an option. This is not a new concept. In 1966, Stradling et al. described observing 119 pneumothoraces, with $80 \%$ requiring no intervention, and allowing the patients to be managed in the outpatient department [7]. However, randomized trials were lacking (until Brown et al. in 2020) [8]. A multicenter, prospective, randomized noninferiority trial was performed in 39 urban and rural hospitals in Australia and New Zealand. A total of 316 patients (age range 14-50) with unilateral moderate to large PSPs were randomized to conservative $(n=162)$ or interventional management $(n=154)$. In the conservative arm, patients were observed for at least $4 \mathrm{~h}$ and repeat chest X-rays (CXRs) were performed. In the intervention arm, small bore ( $\leq 12$ French) chest drains were inserted. If lung re-expansion reoccurred, the drain was clamped for $4 \mathrm{~h}$ and the patient discharged (if the lung stayed up). The primary outcome was complete radiographic resolution of PSP at 8 weeks after randomization using the intention-to-treat analysis. CXR follow-up data at 8 weeks was missing for 23 and 37 patients in the interventional and conservative arms, respectively. When missing data were accounted for, 129 (98.5\%) patients having intervention, and 118 (94.4\%) patients who were managed conservatively, had pneumothorax resolution ( $p=0.02$ for non-inferiority) at 8 weeks. Thus, conservative management was probably non-inferior (defined as $9 \%$ worse or less) to interventional management at 8 weeks, when only patients had CXRs. The conservative arm also had fewer inpatient days and fewer adverse events. However, there are significant limitations. The prespecified noninferiority margin of -9 percent was not based on any previously established values. The missing data of patient follow-up at 8 weeks did not infer significant statistical power to the results, as the conservative management was inferior to interventional management when missing data were included as treatment failure. Moreover, 2637 patients were screened (316 randomized). Thus, exclusion criteria were significant (and the study is not widely applicable). However, conservative management with appropriate safety nets might be an option and further research is required. It is also worth noting that whilst the results met pre-specified endpoints, about $15 \%$ of patients in the conservative group crossed over to review some sort of intervention for their pneumothorax (intercostal drain or equivalent). This in effect represents a treatment intervention, which more than likely contributed to findings of noninferiority with conservative therapy. While appropriately analyzed, with the intent to treat analysis, this can also be seen as a failure rate of $15 \%$ for the conservative approach to management.

Recent guidelines from the British Thoracic Society suggest that ambulatory pneumothorax management (APM) should be the norm concerning the coronavirus 2019 (COVID-19) pandemic [9]. APM is not a new concept. A recent systematic review identified inadequately powered trials as well as studies with high risk of bias, which all professed to show safety of ambulatory pneumothorax management in PSP and SSP [3].

Ambulatory pneumothorax management can be performed with an Atrium Pneumostat chest drain valve, a Heimlich valve, or a rocket ambulatory bag, which are all disposable, single use chest drain devices and valves. Each requires the insertion of an ICD and a subsequent connection. The 8 French Gauge (FG) Rocket ${ }^{\circledR}$ Pleural Vent ${ }^{\mathrm{TM}}(\mathrm{PV})$ is a self-contained drain and valve and is mounted on an 18 Gauge Verres type safety needle.

No adequately designed randomized trials were available until the Randomized Ambulatory Management of Primary Pneumothorax (RAMPP) trial [10]. A total of 776 patients were screened and 236 patients were randomized: 117 patients to the ambulatory care arm and 119 to the standard care arm (NA, ICD, or both). The primary outcome was total length of hospital stay including re-admission up to 30 days after randomization: median hospital stay in the ambulatory care group was 0 days (Interquartile range (IQR) 0-3) and was statistically significant when compared to standard treatment. All 14 serious adverse events occurred in patients who received ambulatory care, eight (57\%) of which were related to the intervention, including for an enlarged pneumothorax, asymptomatic pulmonary edema, and the device malfunctioning, leaking, or dislodging. Hence, AMP is feasible and prevents admissions, but at the expense of greater complications. Trusts were urged to develop local processes to enable ambulatory pneumothorax management. There is also a growing trend to assess air leaks with 
digital suction devices. Hallifax at al performed a prospective study of 81 patients with PSP needing ICD and captured daily digital air leak measurements to determine failure of medical management against prespecified criteria [11]. Treatment failure was associated with an air leak of $\geq 100 \mathrm{~mL} / \mathrm{min}$ on day 1 (adjusted odds ratio (OR) of treatment failure 5.2 (95\% CI 1.2 to $22.6, p=0.03$ )). Validation of the use digital pressure monitoring in the PV group in the RAMPP trial will be a major tool for predicting treatment failure, lowering the risk of SE, and increasing pneumothorax size. Results are eagerly awaited.

There is only one randomized controlled trial of ambulatory devices in SSP [12]. This is very timely as hospitalization for SSP is twice as long as PSP [12]. The study, led by Walker et al., was a multisite study that took place in the United Kingdom. Inclusion criteria were clinical or radiological definitions of SSP as well as feasibility of intercostal drainage. A total of 186 patients were screened, with 20 randomized to standard care and 21 to ambulatory management (with a flutter valve). The trial started off using PV, which resulted in $43 \%$ of serious adverse events and, thus, required a change of device, but not of concept, to an Atrium Pneumostat. This was due to the PV being of a smaller gauge and, thus, not enough for the air leaks associated with SSP. Total hospitalization days within 30 days was 6 (IQR 1-15.5) in the ambulatory care arm and 6 (IQR 2.25-15.5) with standard care $(p=0.77)$. Initial admission for the former was 1 day (IQR 1-14) versus 3.5 days (IQR 2-7) for standard care $(p=0.122)$. Failure of initial treatment in 7 days was $28 \%(n=6)$ with ambulatory care versus $15 \%$ $(\mathrm{n}=3)$ with standard care $(p=0.29 .33(56 \%)$. The adverse events that were in the ambulatory care arm mostly related to enlarging pneumothorax, blockage and development of surgical emphysema. The trial did not reach the intended recruitment, with a high number of exclusions and, thus, the small sample size with the early high failures of the PV (six in the first week) might have contributed to not finding a difference between hospital stay between the two arms. A further trial with the Atrium Pneumostat is now suggested.

\section{Conclusions}

Updated pneumothorax guidelines are expected. New pathways for PSP management are certain. We propose a patient-centered approach where the vast majority of PSPs can be initially observed on an outpatient basis with appropriate safety nets. If intervention if required, ambulatory management with a PV is feasible, as long as local processes exist to manage any complications that might arise. The ideal management of SSP is still up for debate.

Funding: This research received no external funding.

Conflicts of Interest: The authors declare no conflict of interest.

\section{References}

1. Papagiannis, A.; Lazaridis, G.; Zarogoulidis, K.; Papaiwannou, A.; Karavergou, A.; Lampaki, S.; Baka, S.; Mpoukovinas, I.; Karavasilis, V.; Kioumis, I.; et al. Pneumothorax: An up to date "introduction". Ann. Transl. Med. 2015, 3, 53. [CrossRef] [PubMed]

2. MacDuff, A.; Arnold, A.; Harvey, J. Bts pleural Disease Guideline Group. Management of spontaneous pneumothorax: British thoracic society pleural Disease Guideline 2010. Thorax 2010, 65, ii18-ii31. [CrossRef] [PubMed]

3. Brims, F.J.; Maskell, N.A. Ambulatory treatment in the management of pneumothorax: A systematic review of the literature. Thorax 2013, 68, 664-669. [CrossRef] [PubMed]

4. Bintcliffe, O.J.; Hallifax, R.J.; Edey, A.; Feller-Kopman, D.; Lee, Y.C.; Marquette, C.H.; Tschopp, J.M.; West, D.; Rahman, N.M.; Maskell, N.A. Spontaneous pneumothorax: Time to rethink management? Lancet Respir. Med. 2015, 3, 578-588. [CrossRef]

5. Bintcliffe, O.; Edey, A.; Armstrong, L.; Negus, I.; Maskell, N. Parenchymal assessment in primary and secondary pneumothorax. study showing radiological evidence of underlying lung disease including ELCs in the majority of patients defined as having primary spontaneous pneumothorax. Lung Ann. Am. Thorac. Soc. 2016, 13, 350-355. [CrossRef] [PubMed] 
6. Wakai, A.; McCabe, G.; O'Sullivan, R. Simple aspiration versus intercostal tube drainage for primary spontaneous pneumothorax in adults. Cochrane Database Syst. Rev. 2017, 9, CD004479. [CrossRef]

7. Stradling, P.; Poole, G. Conservative management of spontaneous pneumothorax. Thorax 1966, 21, 145-149. [CrossRef] [PubMed]

8. Brown, S.G.A.; Ball, E.L.; Perrin, K.; Asha, S.E.; Braithwaite, I.; Egerton-Warburton, D.; Jones, P.G.; Keijzers, G.; Kinnear, F.B.; Kwan, B.C.H.; et al. Conservative versus interventional treatment for spontaneous pneumothorax. N. Engl. J. Med. 2020, 382, 405-415. [CrossRef] [PubMed]

9. British Thoracic Society. Pleural Services during the COVID-19 Pandemic. Available online: https: //www.brit-thoracic.org.uk/about-us/covid-19-information-for-the-respiratory-community/ (accessed on 22 November 2020).

10. Hallifax, R.J.; McKeown, E.; Sivakumar, P.; Fairbairn, I.; Peter, C.; Leitch, A.; Knight, M.; Stanton, A.; Ijaz, A.; Marciniak, S.; et al. Ambulatory management of primary spontaneous pneumothorax: An open-label, randomised controlled trial. Lancet 2020, 4, 39-49. [CrossRef]

11. Hallifax, R.J.; Laskawiec-Szkonter, M.; Rahman, N.M. RAMPP Trial collaborators. Predicting outcomes in primary spontaneous pneumothorax using air leak measurements. Thorax 2019, 74, 410-412. [CrossRef] [PubMed]

12. Walker, S.P.; Keenan, E.; Bintcliffe, O.; Stanton, A.E.; Roberts, M.; Pepperell, J.; Fairbairn, I.; McKeown, E.; Goldring, J.; Maddekar, N.; et al. Ambulatory management of secondary spontaneous pneumothorax: A randomised controlled trial. Eur. Respir. J. 2020, 2003375. [CrossRef] [PubMed]

Publisher's Note: MDPI stays neutral with regard to jurisdictional claims in published maps and institutional affiliations.

(C) 2021 by the author. Licensee MDPI, Basel, Switzerland. This article is an open access article distributed under the terms and conditions of the Creative Commons Attribution (CC BY) license (http://creativecommons.org/licenses/by/4.0/). 